\title{
DESCRIÇÃO DAS LARVAS DE Psectrogaster amazonica E Potamorhina altamazonica (CURIMATIDAE, PISCES) DA AMAZONIA CENTRAL.
}

\author{
Flávio Lima NASCIMENTO', Carlos ARAÚJO-LIMA²
}

RESUMO - Foram descritas as larvas de Psectrogaster amazonica e Potamorhina altamazonica, obtidas por fecundação artificial. As características morfológicas, morfométricas foram apresentadas segundo a classificação de estádios de desenvolvimento. As larvas das duas espécies podem ser separadas pelo padrão de pigmentação e número de miômeros.

Palavras-chave: Amazônia, larvas de peixes, desenvolvimento larval, Characiformes, Potamorhina, Psectrogaster.

Larval Description of Psectrogaster amazonica and Potamorhina altamazonica (CURIMATIDAE, PISCES) of Central Amazon.

ABSTRACT - Larvae of Psectrogaster amazonica and Potamorhina altamazonica, obtained by artificial fertilization, were described. The morphologic, morphometric characteristics are presented according to the classification of development. The larvae of the two species can be separated by their pigmentation patterns and myomere numbers.

Keywords: Amazon, fish larvae, larval development, Characiforms, Potamorhina, Psectrogaster:

\section{INTRODUÇÃO}

Informações sobre a
identificação das larvas de
Characiformes são importantes para se
entender a ecologia reprodutiva de
peixes da Amazônia Central. Há
informações de correlação da
reprodução e o período larval de várias
espécies de Characiformes com o rio
Amazonas. Algumas espécies, como
Colossomar macropomum,

Potamorhina latior e Mylossoma ssp foram amostradas quando migravam dos lagos de várzea para o canal principal, com gônadas maduras (GOULDING \& CARVALHO, 1982; COX-FERNANDES, 1988). Também existem no rio, grande número de larvas de Characiformes (ARAUJOLIMA, 1984; PETRY, 1989). Estudos detalhados sobre a ecologia das larvas não podem ser realizados, especialmente, devido a falta de conhecimento sobre as larvas e sua identificação. $\mathrm{O}$ desenvolvimento larval das espécies de Characiformes da Amazônia Central é conhecido para apenas 4 espécies (ARAUJO-LIMA, 1985; 1991; ARAUJO-LIMA et al, no prelo) das 132 encontradas por JUNK et al (1983) nesta comunidade.

Neste trabalho apresentamos a descrição das larvas de Psectrogaster amazonica Eigenmann and Eigenmann e Potamorhina altamazonica Cope. Ambas são comuns na calha central do rio Amazonas e têm crescente impor-

CPA Pantanal, EMBRAPA, CP-109, Corumbá, MS, 79320-900

2 DBA, INPA, CP-478, Manaus, AM, 69011 
MATERIAL E MÉTODOS

\section{Obtenção de amostras}

As larvas de Potamorhina altamazonica e Psectrogaster amazonica foram obtidas por fecundação artificial, Os reprodutores de $P$. amazonica foram capturados com malhadeiras de 25 e $30 \mathrm{~mm}$ entre-nós opostos, na embocadura do lago Catalão, no rio Amazonas. Após a extrusão, os reprodutores (6 machos e 3 fêmeas) foram devidamente numerados, fixados em formol a $10 \%$ por 48 horas e posteriormente colocados em álcool etílico comercial a $70 \%$.

A fecundação dos gametas foi feita a seco. Os ovos foram incubados em caixas de isopor com água branca do rio Amazonas. Decorridos 12 horas após a fecundação, os ovos eclodiram e as larvas foram transportadas em sacos plásticos para os aquários no laboratório, onde permaneceram até o final do período larval. A temperatura da água foi mantida próxima à do rio $\left(29^{\circ} \mathrm{C} \pm 1\right.$; ARAÚJO-LIMA, 1984) por estabilizadores automáticos de temperatura, e monitorada a cada trinta minutos por um "Data/Logger". A manutenção da qualidade da água foi feita por filtração biológica, esterilização com raios ultra-violeta e renovação de 80 a $90 \%$ da água a cada 15 dias. A partir do terceiro dia de vida as larvas foram alimentadas 2 vezes ao dia com zooplâncton natural ( $<100$ um), coletado nos tanques da Coordenação de Pesquisa em Aquicultura do INPA, e fornecido na proporção de 1 a 3 indivíduos/ml, seguindo HUNTER (1984).
As larvas de $P$. altamazonica, foram obtidas de uma desova realizada em 1989. Estavam conservadas em formol a $4 \%$ e pertenciam à coleção da Coordenação de Pesquisas em Biologia Aquática do INPA. Essas amostras permitiram descrever a espécie até a fase de mesolarva. O segundo e terceiro estádios de protalarvas, caracterizado pelo surgimento da bexiga natatória e das nadadeiras peitorais, não foram descritos, devido à ausência de exemplares na coleção.

\section{Análise das amostras}

As larvas foram amostradas a cada 12 horas durante a primeira semana e a partir daí, a cada 24 horas. Os exemplares eram anestesiados, antes de serem fixados em formalina a $4 \%$. Para melhor conservação, as amostras foram mantidas na geladeira e abrigadas da luz. Posteriormente, cada larva foi numerada e acondicionada individualmente.

As amostras foram separadas por estádios de desenvolvimento (SNYDER, 1976). As medidas foram tomadas em um estéreo-microscópio com uma ocular micrométrica. As principais medidas corporais foram tomadas segundo ARAUJO-LIMA (1991).

A descrição e registro dos padrões de pigmentação foram realizadas em estéreo-microscópio com fundo branco, levando-se em conta a forma (ramificado, punctiforme ou mancha= vários melanóforos punctiformes unidos), o número e a posição dos melanóforos em relação às estruturas do corpo da larva. As ilustrações foram feitas com auxílio de uma câmara 
clara seguindo as técnicas descritas por FABER \& GADD (1983).

$\mathrm{O}$ número de miômeros totais incluiu todas as unidades, do primeiro occipital incompleto ao último urostilo. $\mathrm{Na}$ contagem dos miômeros pré-anais foram consideradas todas as unidades do primeiro occipital até o último miômero, cortado medianamente pela tangente que passa pela margem anterior do ânus. As contagens de miômeros foram feitas em um microscópio com luz polarizada.

\section{RESULTADOS}

Foram analisadas 376 larvas de Psectrogaster amazonica e 34 larvas de Potamorhina altamazonica, provenientes de três desovas e de uma desova, respectivamente.

Após a fecundação, os ovos de $P$. amazonica ficaram em repouso no fundo da caixa de incubação. Aproximadamente 6 horas após a eclosão, as larvas buscavam a superfície, mantendo esse movimento vertical até o terceiro dia de vida livre, quando passaram a nadar no sentido horizontal.

Descrição da morfologia e pigmentação das larvas de Psectrogaster amazonica Protolarva:

Estádio 1 - recém eclodida (Fig.1):

Comprimento padrão de 2,1 a 2,6 $\mathrm{mm}$. Saco vitelínico grande e elíptico, medindo no comprimento 30 a $45 \%$ e na largura 20 a $30 \%$, em relação ao

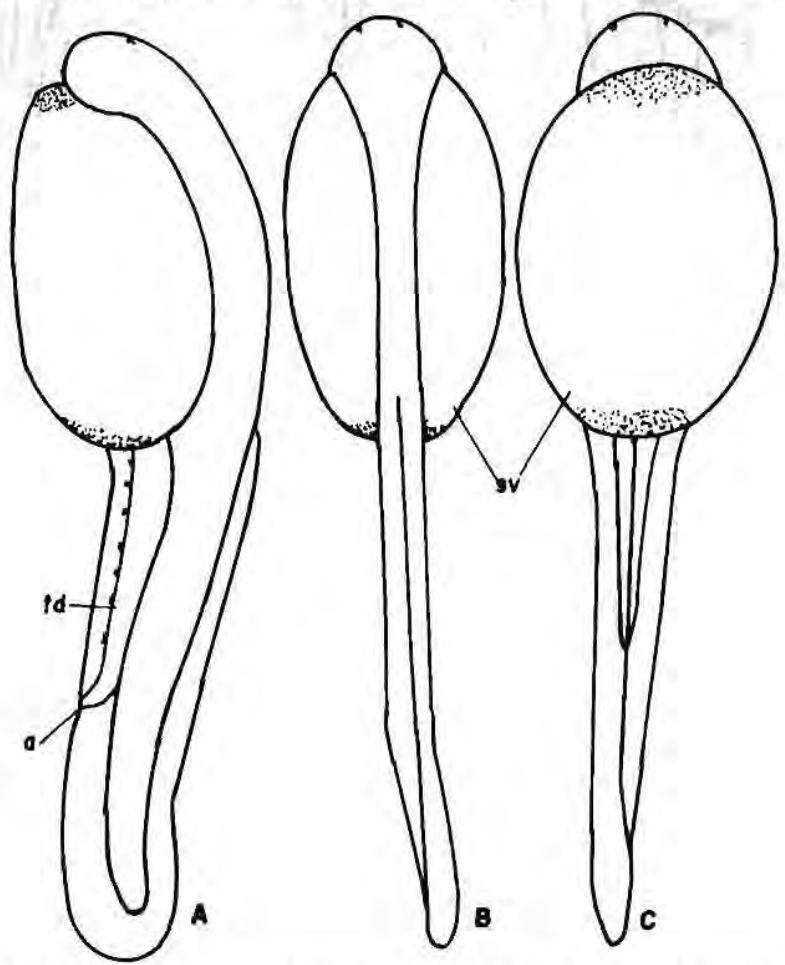

Figura 1. Protolarya de Psectrogaster amazonica (estádio $1-\mathrm{cp}=2,4 \mathrm{~mm})(\mathrm{A}=$ vista lateral; $\mathrm{B}=$ vista dorsal; $\mathrm{C}=$ vista ventral; $\mathrm{sv}=$ saco vitelínico; $\mathrm{td}=$ tubo digestivo; $\mathrm{a}=$ ânus) 
comprimento padrão. Seção da nadadeira embrionária ventral inserida na margem posterior do saco vitelínico.

Todas as larvas com duas manchas triangulares bem definidas no focinho, duas no saco vitelínico: uma na região anterior junto à cabeça $\mathrm{e}$ outra na região posterior junto à nadadeira embrionária. De 1 a 9 melanó- foros na margem superior da seção préanal da nadadeira embrionária ventral.

Estádio 2 - bexiga natatória inflada (Fig.2)

Comprimento padrão de 2,5 a 3,5 $\mathrm{mm}$. Saco vitelínico medindo no comprimento 15 a $23 \%$ e na largura 9 a $12 \%$ em relação ao comprimento padrão. Opérculo definido. Boca sub-terminal.

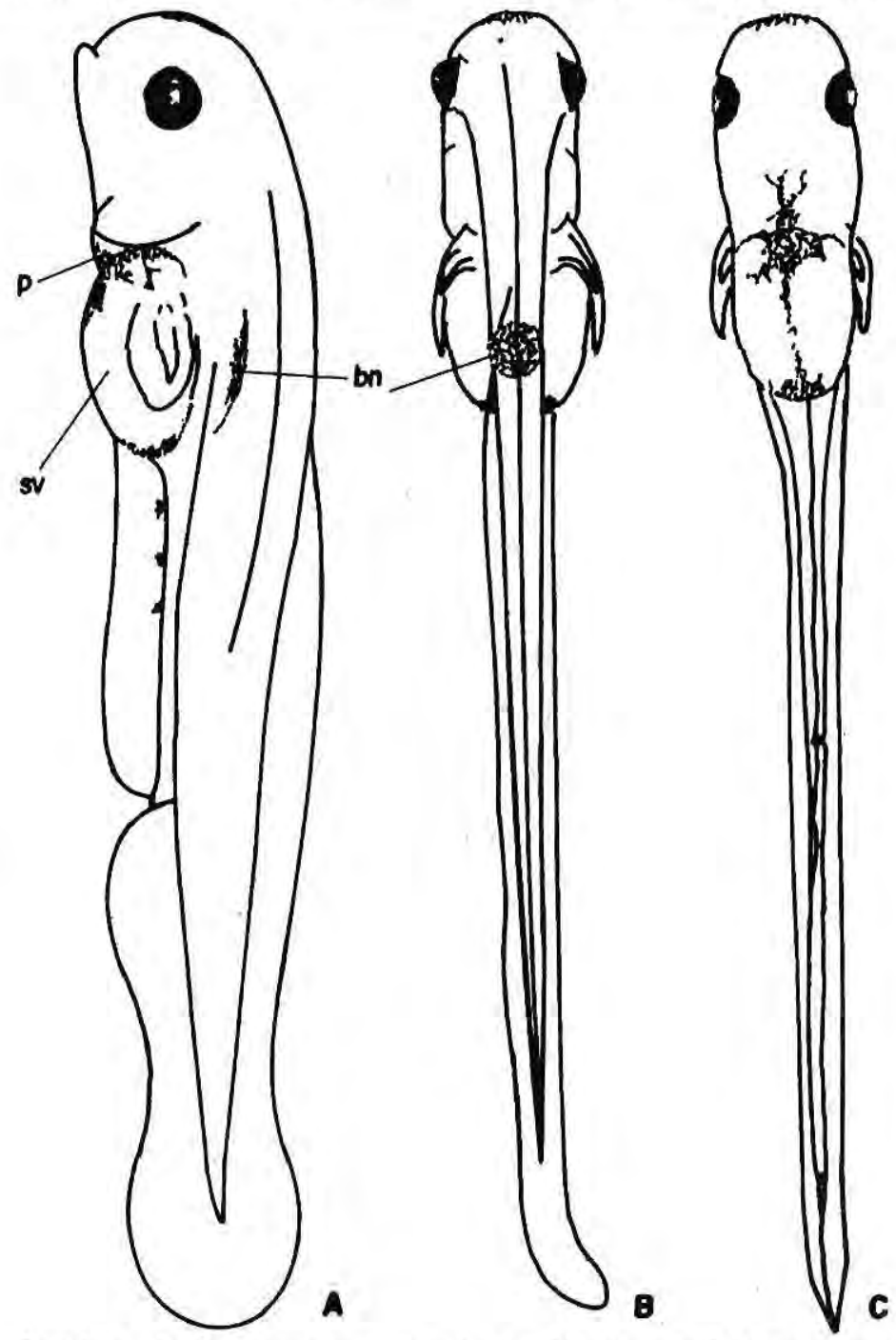

Figura 2: Protolarva de Psectrogaster amazonica (estádio $3-\mathrm{cp}=3,5 \mathrm{~mm})(\mathrm{A}=$ vista lateral; $\mathrm{B}=$ vista dorsal; $\mathrm{C}=$ vista ventral; $\mathrm{bn}=$ bexiga natatória; $\mathrm{sv}=$ saco vitelínico; $\mathrm{p}=$ pericárdio). 
Todas as larvas com olhos totalmente pigmentados. Bexiga natatória inflando e levemente pigmentada na superfície dorsal. Melanóforos espalhados irregularmente sobre o focinho. Mancha de melanóforos da região anterior do saco vitelínico cobrindo a região anterior do pericárdio. Melanóforos na linha mediana ventral do saco vitelínico ligando as manchas da região posterior e anterior. Margem superior da seção pré-anal da nadadeira embrionária ventral com 3 a 9 melanóforos.
Estádio 3 - início da alimentação exógena (Fig.3):

Comprimento padrão de 3,8 a 4,0 $\mathrm{mm}$. Todas as larvas sem saco vitelínico. Boca terminal e articulada, circundada por pequenos melanóforos ramificados. Bexiga natatória pigmentada dorsalmente. Série de melanóforos na parte dorsal do tubo digestivo. Abdômem coberto por uma rede de melanóforos. Melanóforos ramificados no dorso da cabeça e no focinho. Opérculo com manchas externas esparsas.
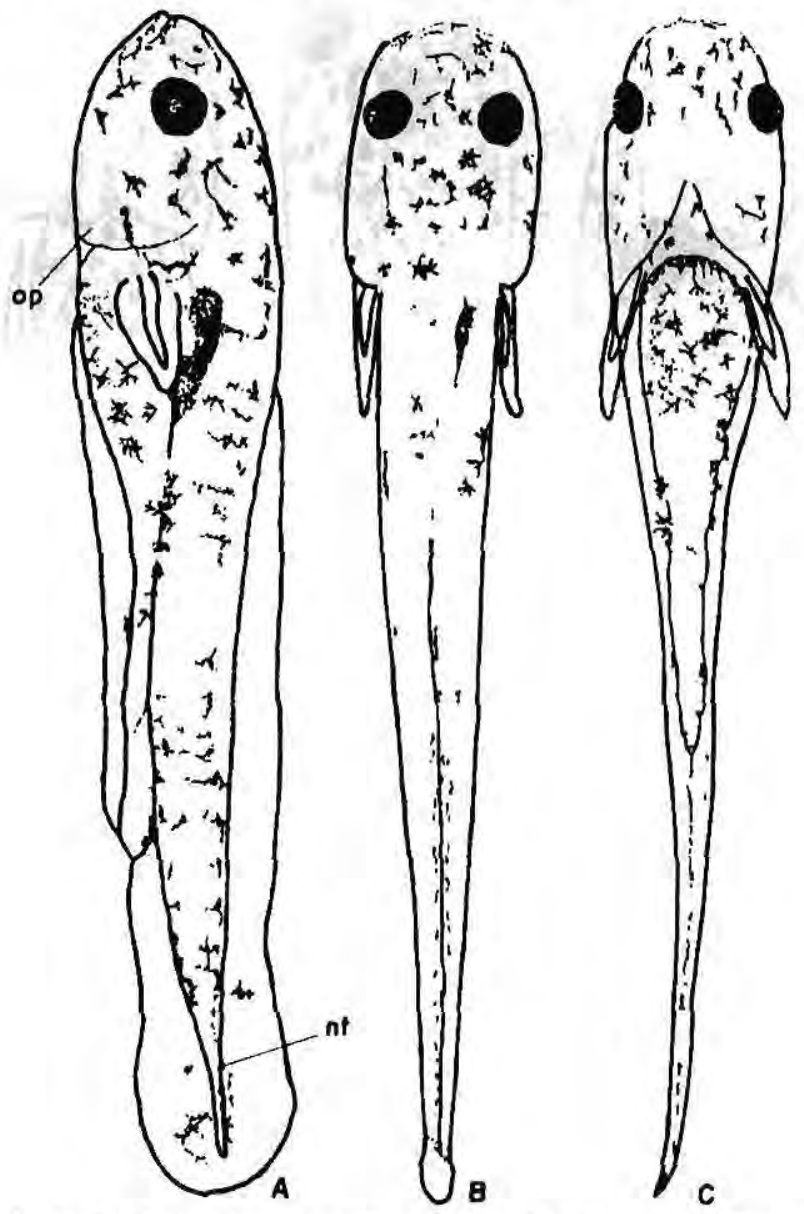

Figura 3. Protolarva de Psectrogaster amazonica (estádio $4-\mathrm{cp}=4,0 \mathrm{~mm})(\mathrm{A}=$ vista lateral; $\mathrm{B}=$ vista dorsal $\mathrm{C}=$ vista ventral; op= opérculo; $\mathrm{nt}=$ notocorda) 
Toda a superfície lateral do corpo com melanóforos ramificados alinhados verticalmente. Nadadeira embrionária ventral com 1 a 3 pequenos melanóforos na margem superior da seção préanal e duas manchas de melanóforos, acima e abaixo do final da notocorda.

Mesolarva - nadadeira caudal em formação (Fig.4).

Comprimento padrão de 6,2 a 7,9 $\mathrm{mm}$. Dentes cônicos no dentário e pré- maxilar. Extremidade da nadadeira embrionária ventral inserida na linha vertical mediana do abdômen. Nadadeira dorsal sem raios, delineada na nadadeira embrionária. Raios na nadadeira caudal.

Todas as larvas com pigmentação externa na cabeça, região ventral e lateral do tubo digestivo. Pigmentação intensa no dorso e porção lateral do tronco até o ânus; a partir daí, pigmen-
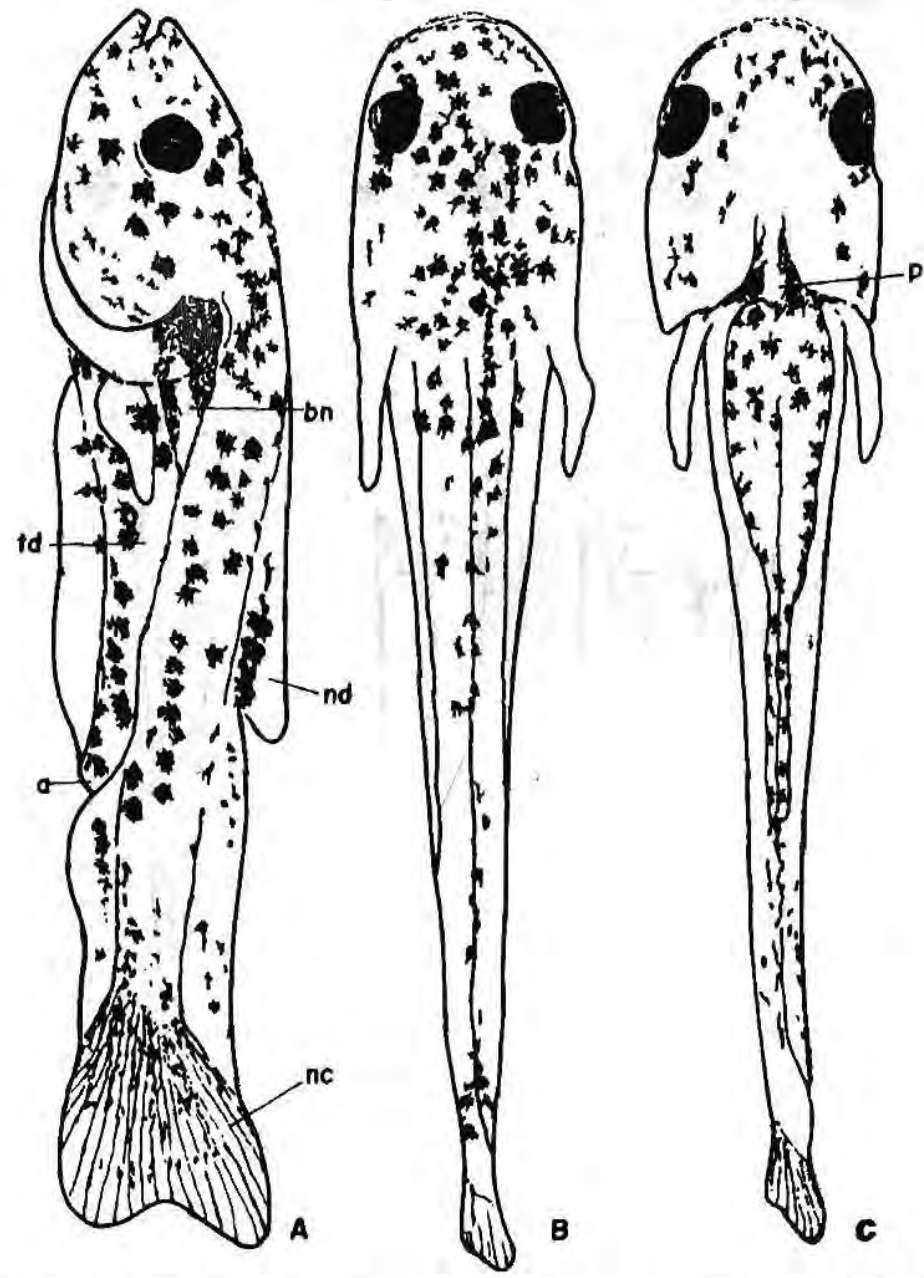

Figura 4: Mesolarva de Psectrogaster amazonica $(\mathrm{cp}=7,2 \mathrm{~mm})(\mathrm{A}=$ vista lateral; $\mathrm{B}=$ vista dorsal; $\mathrm{C}=$ vista ventral; $\mathrm{nd}=$ nad. dorsal; $\mathrm{nc}=$ nad. caudal; $\mathrm{tb}=$ tubo digestivo; $\mathrm{a}=$ ânus; $\mathrm{p}=$ pericárdio; $\mathrm{bn}=$ bexiga natatória). 
tação na parte ventral do tronco até base da nadadeira caudal. Melanóforos na base das nadadeiras dorsal, caudal e na nadadeira embrionária pós-anal. De 1 a 3 melanóforos na margem superior da seção pré-anal da nadadeira embrionária ventral. Pigmentação interna na lateral do pericárdio e dorso da bexiga natatória.

Metalarva - nadadeira ventral presente (Fig.5):
Comprimento padrão de 8 a 13 $\mathrm{mm}$. Todas as nadadeiras com raios. $\mathrm{O}$ número de raios de nove metalarvas foi de 10 a 12 (moda 11) nas nadadeiras dorsal e anal e 9 na nadadeira pélvica. Nas nadadeiras peitoral e caudal não foi possível contá-los. Nadadeira adiposa formada e com pequenos melanóforos punctiformes. Escamas finas e transparentes.

Larvas densamente pigmentadas
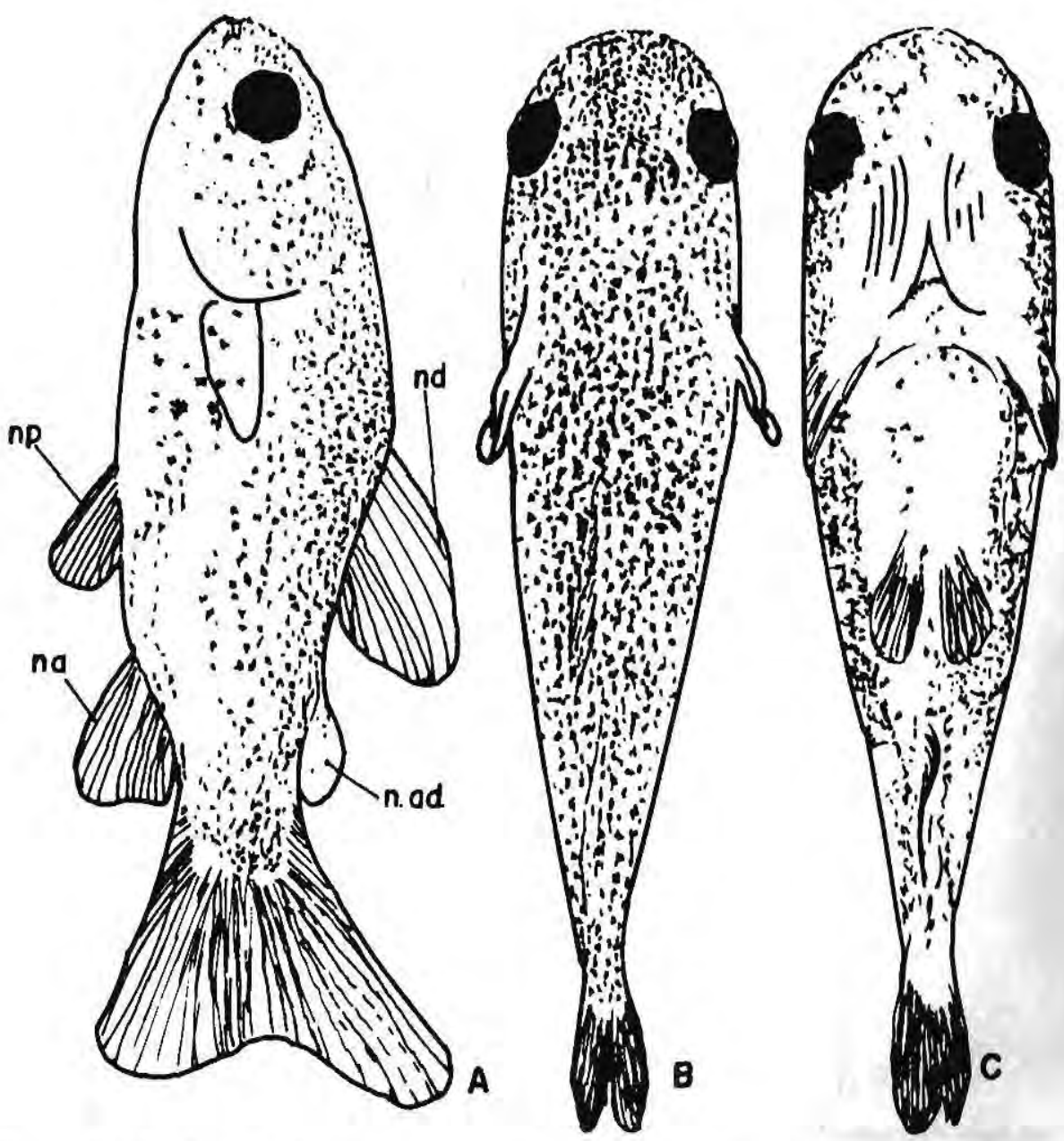

Figura 5. Metalarva de Psectrogaster amazonica $(\mathrm{cp}=9,0 \mathrm{~mm})(\mathrm{A}=\mathrm{vista}$ lateral; $\mathrm{B}=$ vista dorsal; $\mathrm{C}=$ vista ventral; $\mathrm{nd}=$ nad. dorsal; $\mathrm{n} . \mathrm{ad}=$ nad adiposa; $\mathrm{na}=$ nad. anal; $\mathrm{np}=$ nad. pélvica). 
com melanóforos sobre toda sua região dorsal. Porção lateral do abdômen com melanóforos ramificados.

Descrição da morfologia e pigmentação das larvas de Potamorhina altamazonica

Protolarva:

Estádio 1 - recém-eclodida (Fig.6):

Comprimento padrão de 2,1 a 3,0 $\mathrm{mm}$. Saco vitelínico grande e elíptico medindo no comprimento 28 a $32 \%$ e na largura 15 a $17 \%$ em relação ao comprimento padrão. Extremidade anterior da nadadeira embrionária ventral inserida na margem posterior do saco vitelínico.

Todas as larvas com duas manchas triangulares bem definidas no focinho, uma mancha na região anterior do saco vitelínico e um melanóforo no final do tubo digestivo, acima do ânus.

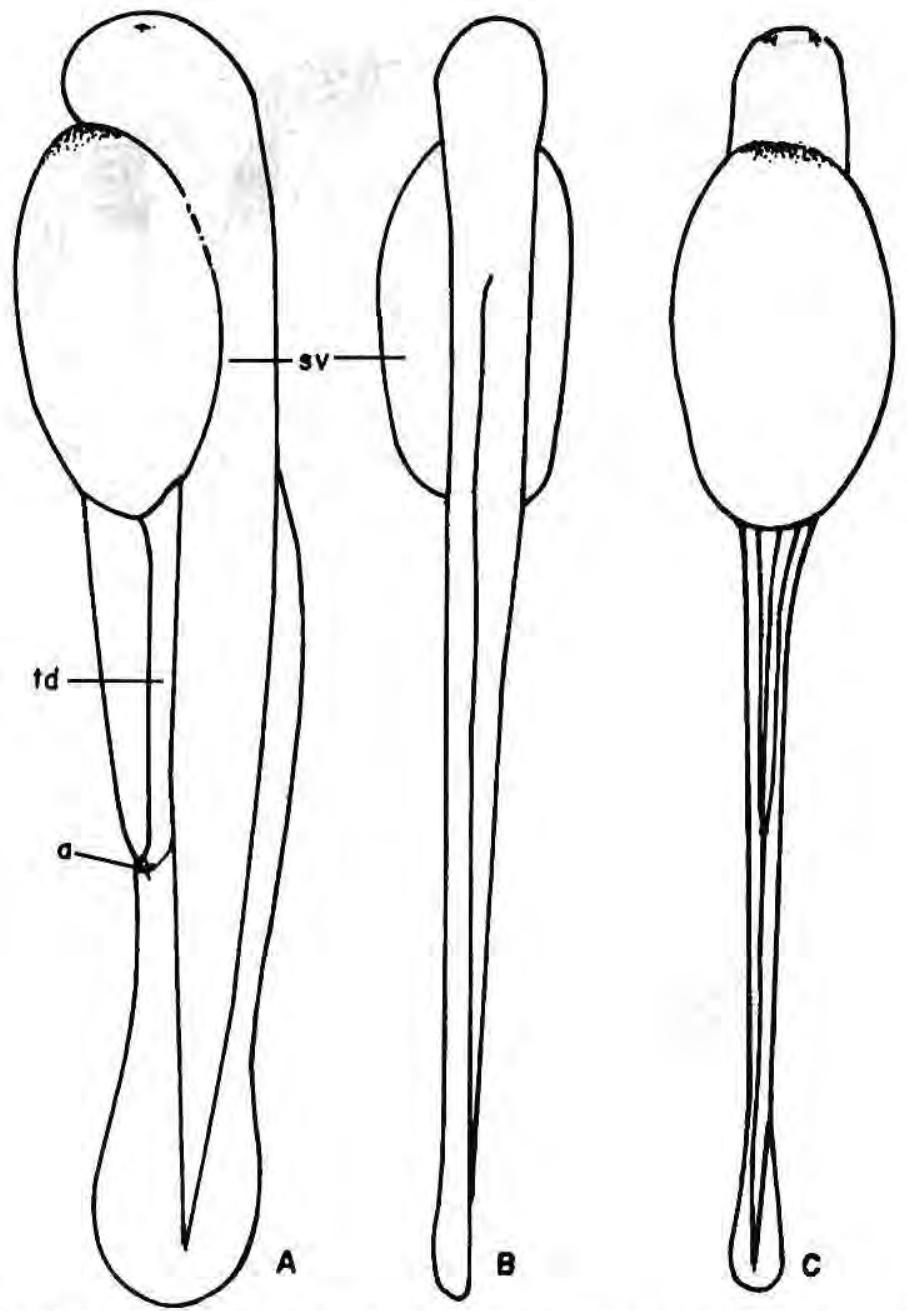

Figura 6. Protolarva de Potamorhina altamazonica (estádio $1-\mathrm{cp}=2,7 \mathrm{~mm})(A=$ vista lateral; $\mathrm{B}=$ vista dorsal; $\mathrm{C}=$ vista ventral; $\mathrm{sv}=$ saco vitelínico; $\mathrm{td}=$ tubo digestivo; $\mathrm{a}=$ ânus). 
Estádio 4 - olhos pigmentados (Fig.7):

Comprimento padrão de 3,5 a 4,0 $\mathrm{mm}$. O saco vitelínico medindo no comprimento de 1 a $2 \%$ e na largura 0,5 a $0,8 \%$ em relação ao comprimento padrão. Extremidade da nadadeira embrionária ventral inserida na linha mediana vertical do estômago. Olhos pigmentados. Boca terminal e articulada.
Todas as larvas com a região anterior do saco vitelínico e o pericárdio cobertos por uma mancha de melanóforos. Bexiga natatória inflada e pigmentada no dorso. Tubo digestivo com melanóforos ramificados na sua região látero-superior e um acima do ânus. Todas as larvas com pigmentação interna marcando a região superior da cavidade branquial. Manchas
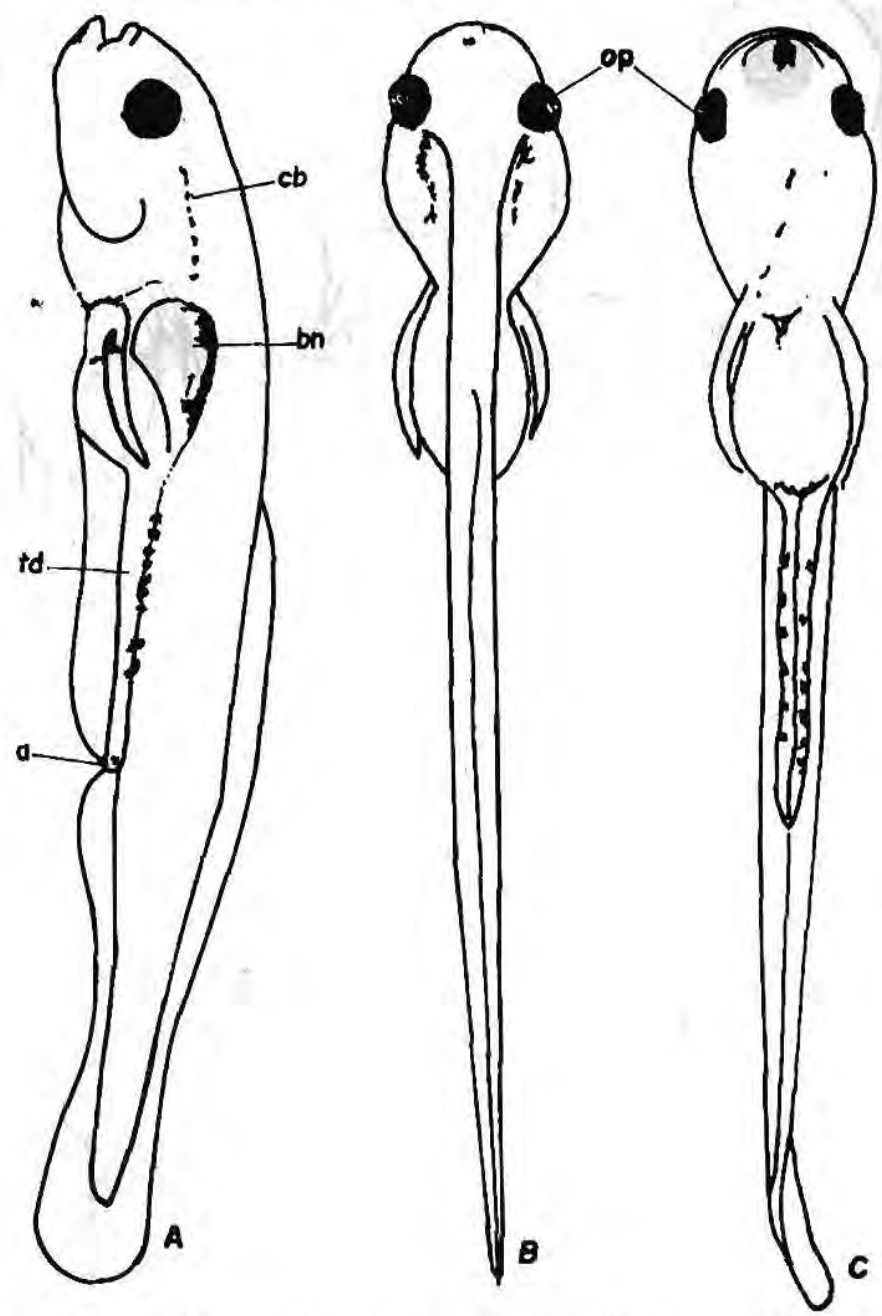

Figura 7. Protolarva de Potamorhina altamazonica (estádio $4-\mathrm{cp}=3,5 \mathrm{~mm})(\mathrm{A}=$ vista lateral; $\mathrm{B}=$ vista dorsal; $\mathrm{C}=$ vista ventral; $\mathrm{op}=$ olhos pigmentados; $\mathrm{td}=$ tubo digestivo; $\mathrm{a}=\mathrm{annus;}$ $\mathrm{cb}=$ cavidade branquial) 
triangulares na região superior do focinho e algumas larvas com um grande melanóforo na região ventral da mandíbula.

Estádio 5 - início da alimentação exógena (Fig.8):

Comprimento padrão de 3,0 a 4,0 $\mathrm{mm}$. Boca terminal, articulada. Saco vitelínico ausente. Alimentação exógena iniciada.

Todas as larvas com pequenos melanóforos espalhados no focinho e na região ventral da mandíbula. Lábios delineados por melanóforos punctiformes. Pigmentação interna na região da cavidade branquial. Bexiga natatória dorsalmente pigmentada. Tubo digestivo com 9 a 11 melanóforos em cada lateral.
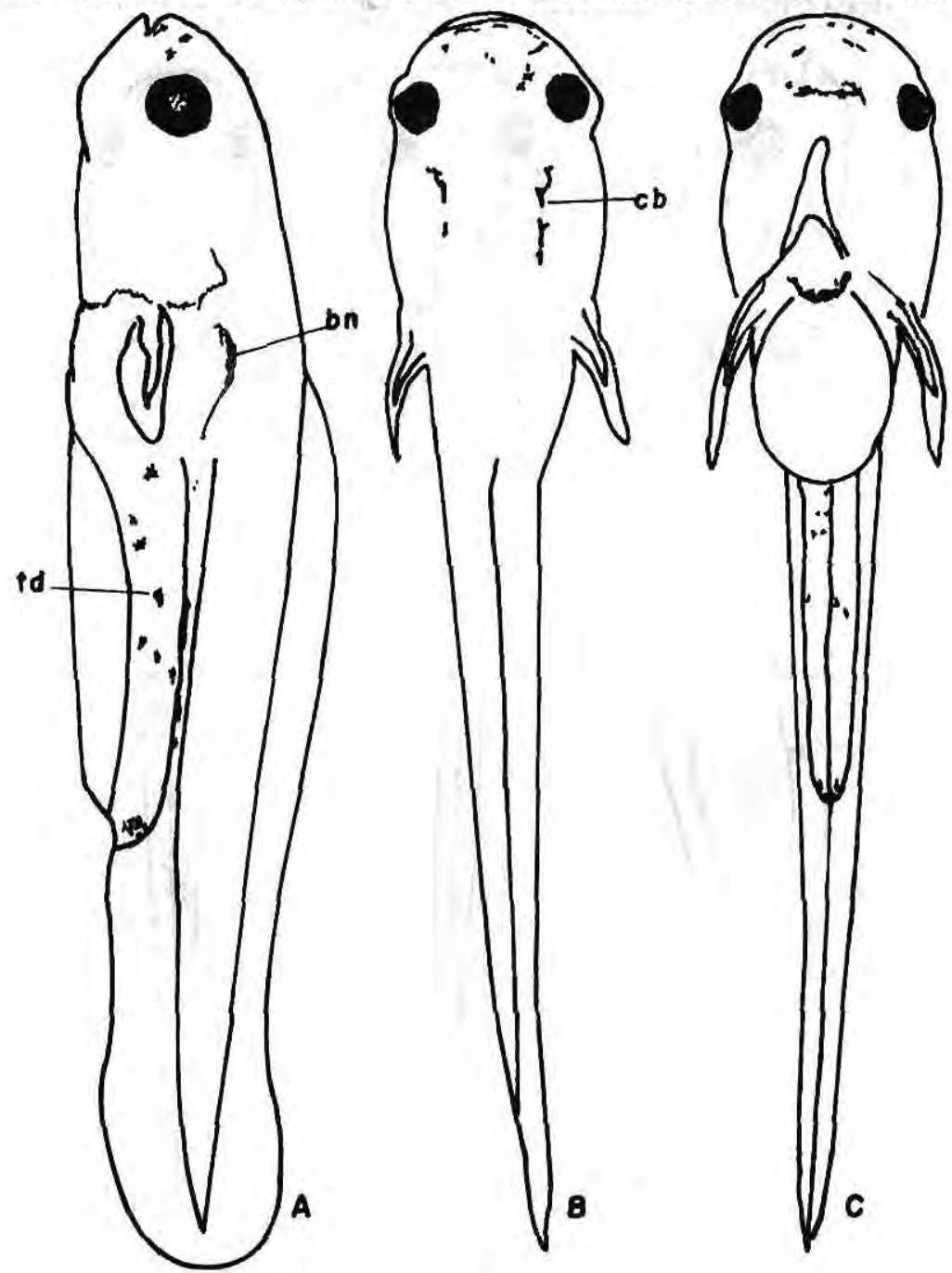

Figura 8. Protolarva de Potamorhina altamazonica (estádio $5-\mathrm{cp}=3,9 \mathrm{~mm})(\mathrm{A}=$ vista lateral; $\mathrm{B}=$ vista dorsal; $\mathrm{C}=$ vista ventral; $\mathrm{cb}=$ cavidade branquial; $\mathrm{bn}=$ bexiga natatória; $\mathrm{t}=$ tubo digestivo) 
Mesolarva (fig.9):

Comprimento padrão de 3,5 a 4,0 $\mathrm{mm}$. Dentes cônicos no dentário e prémaxilar. Extremidade da nadadeira embrionária ventral inserida ventralmente a $36 \%$ do comprimento padrão. Nadadeira dorsal com os primeiros raios. Nadadeira caudal com raios não bifurcados.

Todas as larvas com melanóforos esparsos no dorso da cabeça, vários melanóforos punctiformes no dentário e ventralmente na mandíbula. Abdômen com pigmentação esparsa nas regiões lateral e ventral. Vários melanóforos distribuídos ao longo das laterais do tubo digestivo, pequenos melanóforos formando um anel próximo ao ânus. Pequenos melanóforos punctiformes entre os raios da nadadeira caudal. Mancha de melanóforos na nadadeira embrionária pós-
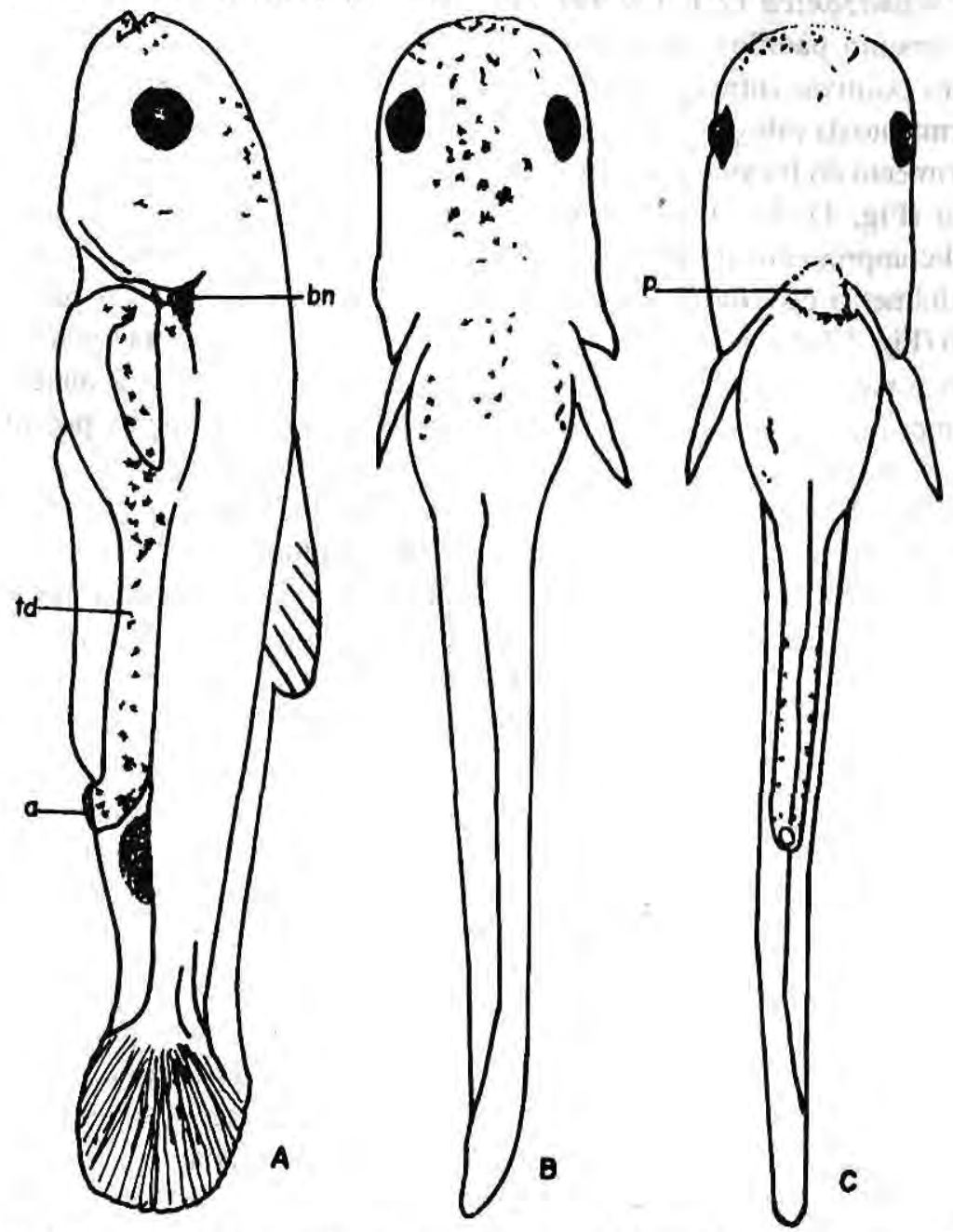

Figura 9 Mesolarva de Potamorhina altamazonica $(\mathrm{cp}=4,0 \mathrm{~mm})(A=$ vista lateral; $B=$ vista dorsal; $\mathrm{C}=$ vista ventral; $\mathrm{td}=$ tubo digestivo; $\mathrm{a}=$ ânus; $\mathrm{b} n=$ bexiga natatória; $\mathrm{p}=$ pericárdio) 
anal junto ao corpo, seguida de pequenos melanóforos até a base da nadadeira caudal. Bexiga natatória e pericárdio intensamente pigmentados na face anterior.

Morfometria das larvas de Psectrogaster amazonica e

\section{Potamorhina altamazonica}

As protolarvas de $P$. amazonica (2,1 a 4,2 mm de comprimento padrão) e $P$. altamazonica $(2,1$ a $4 \mathrm{~mm}$ de comprimento padrão), apresentaram relações positivas entre $\mathrm{cp}$ e as razões: comprimento da cabeça/cp (Fig. 10-A), comprimento do focinho/comprimento padrão (Fig. 11-A), distância interorbital/comprimento padrão (Fig. 11C) e diâmetro do olho/comprimento padrão (Fig. 12-A). As relações foram negativas para: comprimento pré-dorsal/comprimento padrão (Fig. 10-B), comprimento pré- ventral/comprimento padrão (Fig. 10-C) e comprimento préanal/comprimento padrão (Fig. 11-B). As relações nas mesolarvas se mantiveram praticamente constantes para todas as medidas (Fig. 10,11 e 12). Houve sobreposição entre as duas espécies em todas as medidas.

Nas 139 protolarvas de $P$. amazonica analisadas, o número de miômeros totais variou de 32 a 33 $($ moda $=32)$ e os pré-anais de 21 a 23 $(\operatorname{moda}=21)$. As protolarvas de $P$. altamazonica apresentaram o número de miômeros totais e pré-anais constantes em 37 e $23(n=29)$, respectivamente (Fig. 12). O número de miômeros totais separa as duas espécies.

\section{DISCUSSÃO}

Comparando-se as descrições de Psectrogaster amazonica e Potamorhina altamazonica, nota-se que os caracteres de pigmentação e número de miômeros são os mais importantes para diagnosticar as duas espécies. A sobreposição dos dados morfométricos inviabilizam sua utilização na separação das larvas.

A contagem do número de miômeros totais separou Psectrogaster amazonica d Potamorhina altamazonica e de $P$. latior descrita por Araujo-Lima (1991), mas não Potamorhina latior de Potamorhina altamazonica (fig. 13). A presença de pigmentação apenas na região anterior do saco vitelínico e a ausência de melanóforos na seção pré-anal da nadadeira embrionária das duas espécies de Potamorhina é uma característica adicional marcante para separá-las de Psectrogaster amazonica. $\mathrm{O}$ padrão de pigmentação, entretanto, não difere as protolarvas de $P$. altamazonica de $P$. latior. Apenas na fase de mesolarva é possível distinguilas, pois $P$. latior tem o dorso mais pigmentado e não apresenta mancha de melanóforos na região da nadadeira anal, como P. altamazonica.

A presença de um melanóforo na testa das protolarvas parece ser uma característica da família, pois estava presente nas três espécies. Seria interessante checar sua presença nas larvas de Psectrogaster rutiloides, Potamorhina pristigaster e outras 

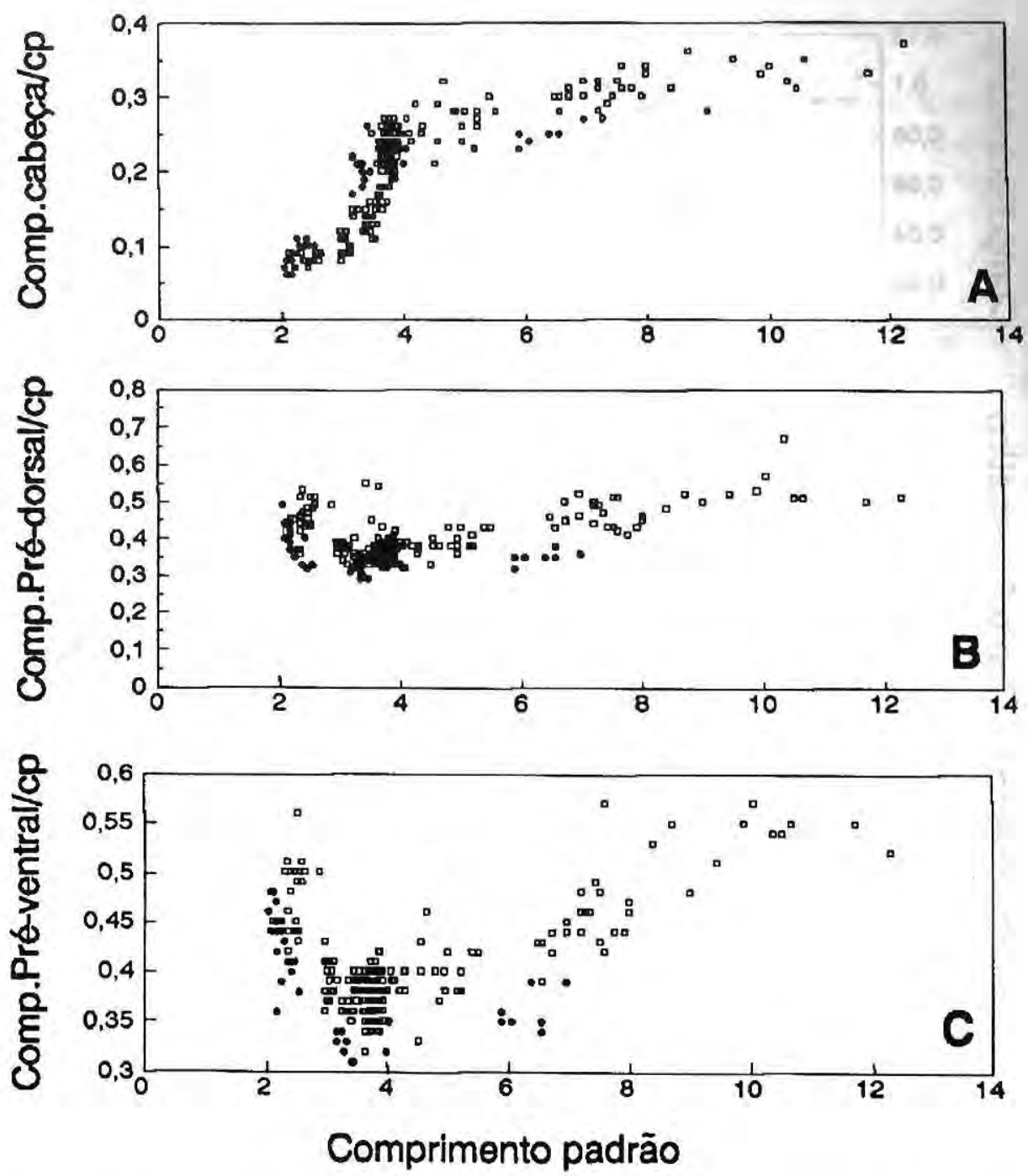

Figura 10. Variação das razões do Comprimento da cabeça/ Comprimento padrão (A), Comprimento pré-dorsal/ Comprimento padrão (B), Comprimento pré-ventral/ Comprimento padrão (C), em função do comprimento padrão para Psectrogaster amazonica (quadrado vazado) e Potamorhina altamazonica (círculo cheio) 

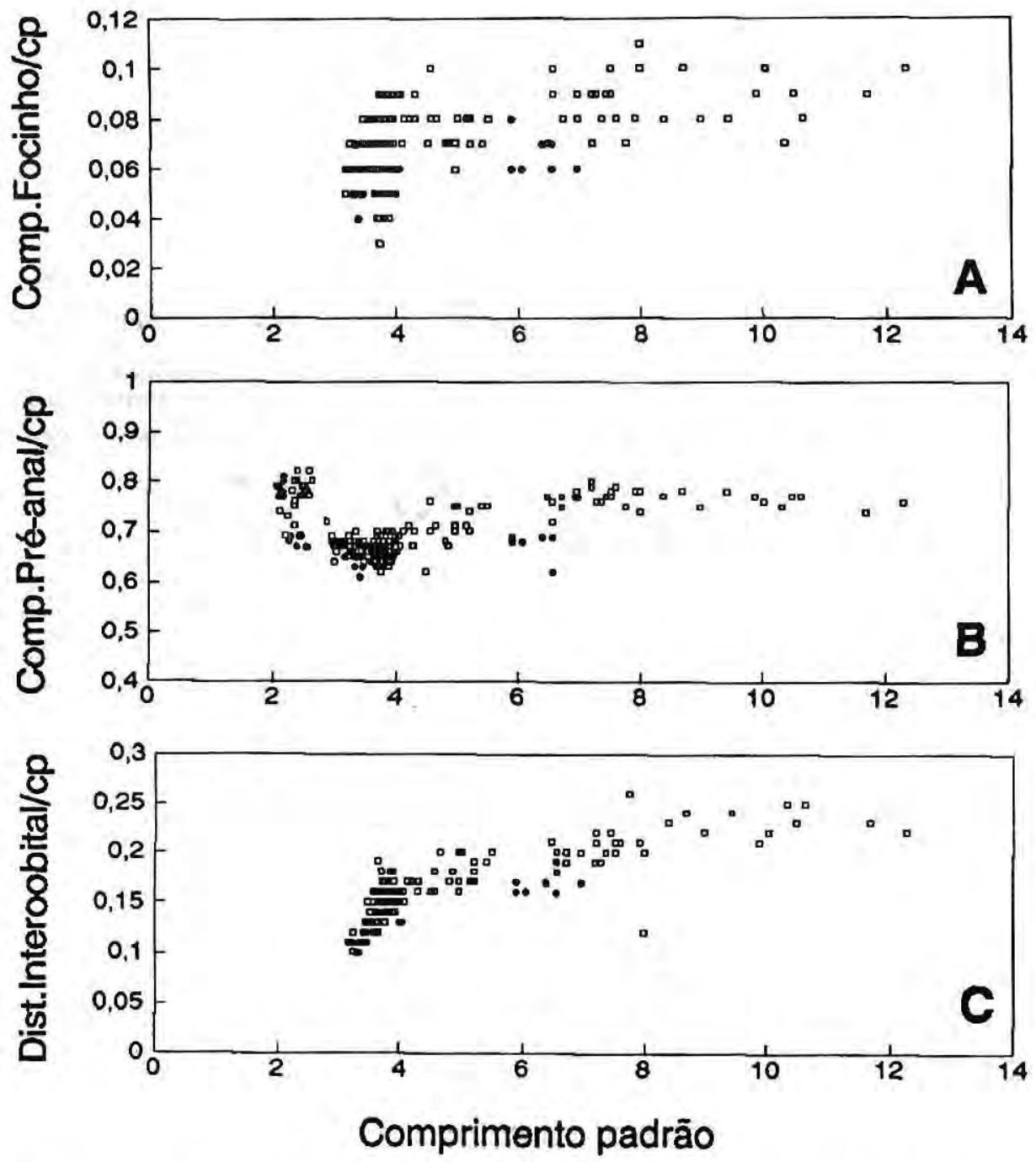

Figura 11. Variação das razões do Comprimento do focinho/ Comprimento padrão (A), Comprimento pré-anal/ Comprimento padrão (B), Distância interorbital/ Comprimento padrão (C), em função do comprimento padrão para Psectrogaster amazonica (quadrado vazado) e Potamorhina altamazonica (círculo cheio) 


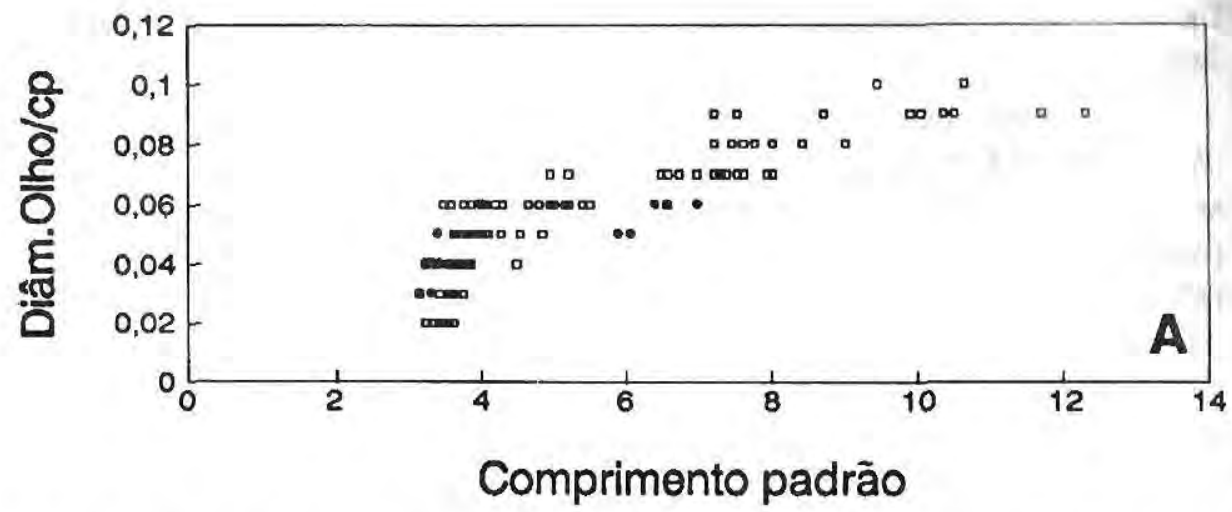

Figura 12. Variação das razão do Diâmetro do olho/ Comprimento padrão (A), em função do comprimento padrão para Psectrogaster amazonica (quadrado vazado) e Potamorhina altamazonica (círculo cheio)

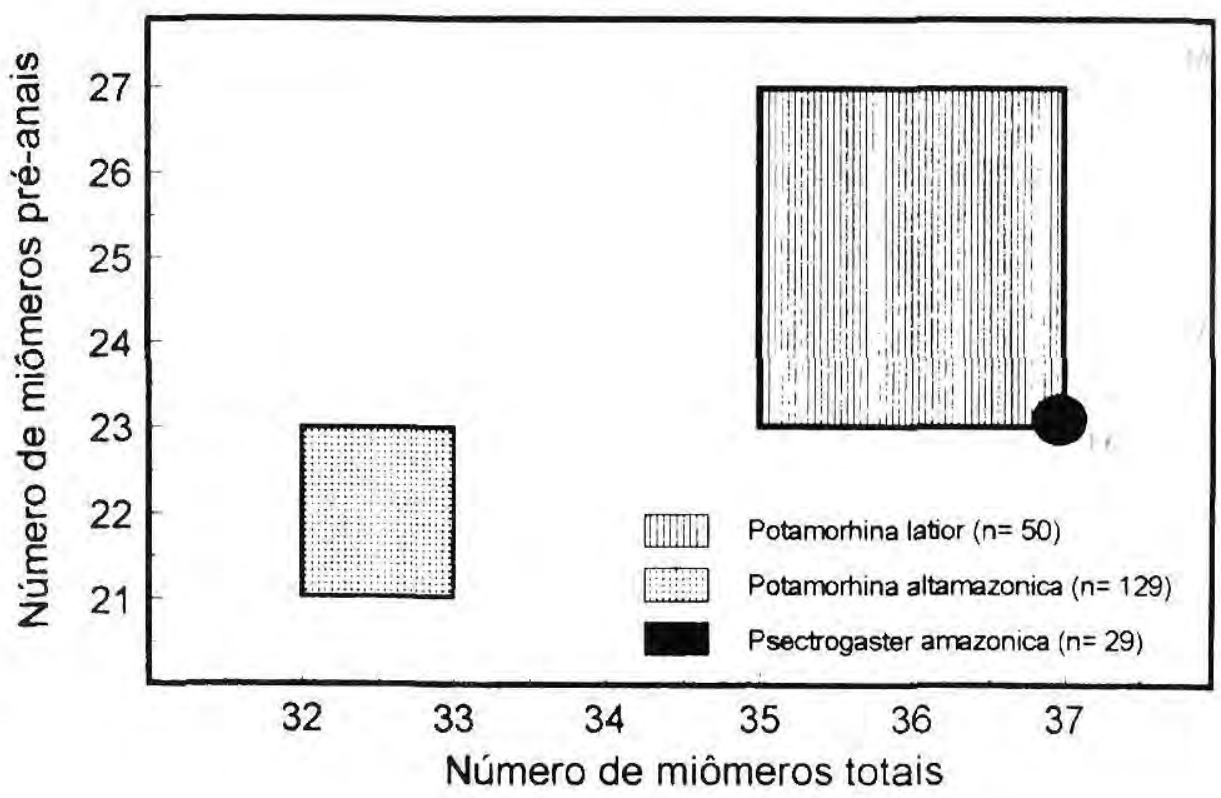

Figura 13. Frequências do número de miômeros pré-anais e totais para Psectrogaster amazonica, Potamorhina latior (Araujo-Lima, 1991), Potamorhina altamazonica 
próximas. Este é um caracter conspícuo e que seria de grande valor para a identificação das larvas da família em análise de amostras do rio Amazonas.

As larvas de Potamorhina altamazonica e Psectrogaster amazonica se distinguem de Semaprochilodus insignis (ARAUJO-LIMA, 1985) e Mylossoma spp (ARAUJO-LIMA et al, no prelo) outras duas espécies que ocorrem no rio Amazonas, por serem menores e pelo número reduzido de miômeros.

\section{Literatura Citada}

ARAUJO-LIMA, C. A. R. M.- 1984. Distribuição espacial e temporalde Characiformes em um setor do rio Solimões/Amazonas próximo a Manaus. Dissertação de mestrado INPA-FUA, Manaus, 81 p.[não publicado]

ARAUJO-LIMA, C. A. R. M.- 1985. Aspectos biológicos de peixes amazônicos. V. Desenvolvimento larval do jaraquiescama grossa, Semaprochilodus insignis (Characiformes, Pisces) da Amazônia Central. Rev, Bras. Biol., 45: 423-431.

ARAUJO-LIMA, C. A. R. M.- 1991. A larva de branquinha comum, Potamorhina latior (Curimatidae, Pisces) da Amazônia Central. Rev. Bras. Biol., 51: 45-56.
ARAUJO-LIMA, C.A.R.M; KIROSVSKY, A. L. \& MARCA A. G.. As larvas dos Pacus.Mylossoma spp (Teleostei, Characidae), da Amazônia Central. Rev. Bras. Biol.,[ no prelo].

COX-FERNANDES, C.- 1988. Estudos de migrações laterais de peixes no sistema lago do Rei (Ilha do Careiro) - AM. Dissertação de Mestrado INPA-FUA, Manaus. $170 \mathrm{p}$.[não publicado]

FABER, D. J. \& GADD, S.- 1983. Several drawing techniques to illustrate larval fishes. Trans. Am. Fish. Soc., I12: 349353.

GOULDING, M. \& CARVALHO, M.L.- 1982. Life history and management of the tambaqui (Colossoma macropomum, Characidae): An important Amazonian food fish. Rev. Bras. de Zoologia, 1:107133.

HUNTER, J. R.- 1984. Synopsis of culture methods for marine fish larvae. American Society lcthyologists and Herpetologists. Special Publication, 1: 24-27.

PETRY, P.- 1989. Deriva do ictioplâncton no paraná do Rei, várzea do Careiro, Amazônia central, Brasil. Dissertação de Mestrado INPA-FUA, Manaus, 68p. [não publicado]

SNYDER, D. E.- 1976. Terminologies for intervals of larval fish development. In J. Boreman editor. Great Lakes fish egg and larval identification: proceedings of a workshop. United States Fish and Wildlife Service, FWS/OBS-76/23, Ann Arbor, Michigan, USA. 